\title{
THE EFFECT OF REPEATED APPLICATIONS OF HEAT ON SPERMATOGENESIS IN THE RAT: A HISTOLOGICAL STUDY
}

\author{
K. BOWLER \\ Department of Zoology, University of Durham \\ (Received 17th December 1970, accepted 6th fuly 1971)
}

\begin{abstract}
Summary. The effect of repeated exposures of rat testes to $43.5^{\circ} \mathrm{C}$ has been studied, allowing a 6 -week recovery period between treatments. Following exposure to heat, the weight of the testes was lower than in normal males, even in the twelve males which recovered fertility within 24 weeks following the seventh treatment. No significant changes were found in seminal vesicle weight.

Seminiferous tubules were either normal in histological appearance, or showed 'partial' or 'severe' damage 6 weeks after each application. The percentage of 'severely' atrophic tubules increased by about $4 \%$ with successive heatings. It is concluded that such damage occurred in tubules in which stem cells were dividing at the time of heating and that, as a consequence, their regenerative capacity was severely impaired.
\end{abstract}

\section{INTRODUCTION}

The damaging effect of heat on the germinal epithelium of the mammalian testis is now well documented. The early work on natural and experimental cryptorchidism in guinea-pigs and rats (Moore, 1924) and sheep (Moore \& Oslund, 1923) led to the conclusion that spermatogenesis in the male mammal requires, for normal functioning, a temperature lower than body temperature. Indeed, it was suggested that the scrotum acts as a temperature regulator for the testes (Moore \& Quick, 1924). At this time also, the effect of exposure of guinea-pig testes to higher than physiological temperatures for short duration was determined (Young, 1927, 1929). These early studies tended to be descriptive of the morphological changes which occurred. It is only comparatively recently that any quantitative work has been attempted. For example, Clegg (1963) has shown that cryptorchidism in rats leads to degenerative changes in the seminiferous tubules which are maximal after 15 days, after which a limited regeneration occurs. He found that the spermatogonia were the least affected cells, although both mitoses and meioses were partially inhibited. Steinberger \& Dixon (1959) concluded, from work on rats, that the primary spermatocyte stage was the most sensitive to exposure at temperatures in the range of 41 to $43^{\circ} \mathrm{C}$, and that, following exposure to higher temperatures, a more general non-specific response was found. Later work (Chowdhury \& Steinberger, 1964) showed that not all spermatocytes are equally affected, after exposure of the 
testes to $43^{\circ} \mathrm{C}$ for $15 \mathrm{~min}$, and that the early stages of spermatid development are also heat-sensitive. More recently, Collins \& Lacy (1969) have given the most detailed account to date of the effect of a single application of heat on spermatogenesis. They, too, found the late primary spermatocyte and transitional cells to be the most temperature-sensitive but, as the heat-dose was increased, other stages became susceptible as well. They concluded that the most resistant cells were the spermatogonia followed by resting spermatocytes and late spermatids.

Little work has been carried out on the effect of repeated applications of heat on spermatogenesis. Venkatachalam \& Ramanathan (1962) reported a generalized atrophy of the tubular epithelium following daily exposures (monkeys) or twice-daily exposures (rats) for $20 \mathrm{~min}$ to $44^{\circ} \mathrm{C}$ for 6 days a week for 8 weeks. They gave no further histological details of the damage which occurred, nor whether the epithelium later regenerated.

The purpose of the present study was to determine the effect of repeated heat treatments (allowing for partial recovery to occur between heatings) on the histological appearance of the seminiferous epithelium in rats, and to relate this to earlier work (Bowler, 1967) which showed that seven applications of heat delayed the recovery of fertility by some 48 days, compared with the recovery after a single application.

\section{MATERIALS AND METHODS}

The albino rats used in this study were those males which had been used in the parallel study on the effects of repeated heat applications to the testes on fertility (Bowler, 1967).

The rats were anaesthetized with an intraperitoneal injection of nembutal before the application of heat. The testes were heated by immersing the males up to the level of the penis in a water bath. The temperature of the bath was maintained at $43.5 \pm 0 \cdot 1^{\circ} \mathrm{C}$, and the duration of heat exposure was $20 \mathrm{~min}$ in all cases. Rats had their testes heated from once to seven times depending upon the individual. A 42-day recovery period was allowed between each successive heat treatment. This period allowed substantial but not complete regeneration to occur. Six animals were killed 41 days after each of the second, third, fourth, fifth and seventh treatments. The fourteen animals remaining at the end of the experiment, 24 weeks after the seventh and final heat treatment, were also killed.

At autopsy, the testes were removed, freed from connective tissue and blood vessels and weighed. The seminal vesicles were also dissected out and weighed. Each testis was cut into half through the equator and fixed in Orth's medium. The tissue was embedded in paraffin wax and 5- $\mu \mathrm{m}$ transverse sections were taken of each testis across the equator. The sections were then stained with the periodic acid-Schiff technique after Leblond \& Glermont (1952).

The testis and seminal vesicles of six control animals were treated in the same way as described for the experimental heat-treated animals.

The stained sections were examined and the stage in the cycle was determined for at least ninety and not more than 180 cross sections of tubules from each 
rat. The fourteen stages of the cycle were defined according to the description of Leblond \& Clermont (1952). Tubules from experimental animals were also classified under two further headings.

'Partially' damaged tubules. These were tubules which were so badly damaged that the stage of the cycle could not be determined with certainty, but they still contained some normal germ cells and were in a state of repopulation (Pl. 1, Fig. 1).

'Severely' damaged tubules. These tubules contained no normal germ cells, but only Sertoli cells and/or degenerating germ cells (Pl. 1, Fig. 2).

\section{RESULTS}

\section{Organ weights}

The changes which occurred in testes and seminal vesicle weights in response to the heat treatments are shown in Table 1. The organ weights are expressed as organ wet weight/100 $\mathrm{g}$ body weight. It should be emphasized that the organ weights were obtained after allowing 6 weeks' recovery from the previous scrotal heating, and thus represent the ability of the organs to repair or respond to heat treatments.

\section{TABLE 1}

GHANGES IN MEAN WEIGHTS OF RAT TESTES AND SEMINAL VESICLES AS A RESPONSE TO REPEATED 20 -MIN EXPOSURES OF THE TESTES TO $43.5^{\circ} \mathrm{C}$

\begin{tabular}{|c|c|c|c|c|c|}
\hline $\begin{array}{c}\text { No. of } \\
\text { heat } \\
\text { exposures }\end{array}$ & $\begin{array}{c}\text { Mean body wt } \\
(g)\end{array}$ & $\begin{array}{l}\text { No. of } \\
\text { animals }\end{array}$ & $\begin{array}{c}\text { Mean testes } w t \\
(g / 100 \mathrm{~g} \text { body } w t)\end{array}$ & $\begin{array}{c}\text { Mean seminal } \\
\text { vesicle wt } \\
(\mathrm{g} / 100 \mathrm{~g} \text { body } w t)\end{array}$ & $\begin{array}{c}\text { Recovery } \\
\text { time } \\
\text { (weeks) }\end{array}$ \\
\hline $\begin{array}{l}\text { Control } \\
\text { Two } \\
\text { Three } \\
\text { Four } \\
\text { Five } \\
\text { Seven }\end{array}$ & $\begin{array}{l}314 \cdot 1 \pm 10 \cdot 5 \\
405 \cdot 5 \pm 12 \cdot 6 \\
401 \cdot 0 \pm 27 \cdot 4 \\
393 \cdot 5 \pm 22 \cdot 8 \\
462 \cdot 0 \pm 22 \cdot 4 \\
433 \cdot 5 \pm 23 \cdot 7\end{array}$ & $\begin{array}{l}6 \\
6 \\
6 \\
6 \\
6 \\
6\end{array}$ & $\begin{array}{l}0.948 \pm 0.04 \\
0.463 \pm 0.03 \\
0.409 \pm 0.03 \\
0.403 \pm 0.03 \\
0.341 \pm 0.04 \\
0.371 \pm 0.03\end{array}$ & $\begin{array}{l}0.361 \pm 0.02 \\
0.348 \pm 0.05 \\
0.316 \pm 0.05 \\
0.321 \pm 0.03 \\
0.362 \pm 0.05 \\
0.363 \pm 0.03\end{array}$ & $\begin{array}{l}6 \\
6 \\
6 \\
6 \\
6\end{array}$ \\
\hline Seven & $487 \cdot 4 \pm 17 \cdot 6$ & 12 & $0.339 \pm 0.02$ & $0.351 \pm 0.03$ & 24 \\
\hline
\end{tabular}

The most significant change in weight of the testes had taken place as a result of the first two heat treatments. The weight was found to have fallen to about half the normal value $(P=0.01)$. Some of the changes in weight which occurred after the second heating are statistically significant. For example, the mean weight after the fifth $(P=0.02)$ and seventh $(P=0.01)$ exposures were lower than the mean weight after the second heating. It is of interest that the mean weight of the testes of the twelve animals which recovered fertility within the 24-week recovery period following the seventh application of heat was significantly less than that of normal males $(P=0.001)$. In fact, there was no significant change in testis weight between the males allowed 6 weeks' recovery and those allowed 24 weeks' recovery.

None of the changes seen in seminal vesicle weight following heat treatment were statistically different from those of normal control males (Table 1). 
The organ weights of the two animals which had not recovered fertility within the 24-week recovery period were as follows: weight of testes $/ 100 \mathrm{~g}$ body weight, 0.2562 and $0.3458 \mathrm{~g}$, and weight of seminal vesicles $/ 100 \mathrm{~g}$ body weight, 0.2728 and $0.2168 \mathrm{~g}$. For both of these rats, the values for organ weights fell within the range obtained from the males which had regained fertility following the same number of heat applications, and so they cannot be considered as different.

\section{Histological appearance of the testes}

In the experimental group, the only consistent difference in histological appearance of the cross sections taken from rats killed 41 days following the second, third, fourth, fifth and seventh heat treatments was that the mean percentage of 'severely' damaged tubules increased after each treatment (Table 2). Otherwise, the tubules could be classified as being in one of three conditions. In some, the epithelium had completely regenerated and possessed all the cellular elements normal for that stage whereas, in others, the epithelium was incomplete in that it lacked one generation of germ cells, usually spermatids in the 'maturation stages' ( $\mathrm{Pl}$. 1, Fig. 3). In such tubules, the stage in the cycle could be estimated with reasonable certainty from the 'cap-phase' spermatids and spermatocytes present. The third class of tubules were the ones which were 'partially' damaged. In the group of rats which were allowed a 24-week recovery period following the seventh heat application, almost all tubules were either denuded of germ cells or were normal in appearance, having a complete epithelium. The typical appearance of the testis in this group of animals is shown in PI. 1, Fig. 4.

These results are shown in more detail in Table 2, where they are presented as the mean percentage of tubules in each stage of the cycle, or which show 'partial' or 'severe' damage.

The data for the six control animals which were unheated are in good agreement with similar results for rats in the literature (Clermont \& Harvey, 1965). The differences seen may be due to the different strains of rats which were used in the two studies (see Clermont, Leblond \& Messier, 1959), though Rooij (1968) has also pointed out that different observers may well interpret the drawings of Leblond \& Clermont (1952) somewhat differently.

The clearest point which emerges from this work is that the percentage of tubules severely damaged rose from about $8 \%$ in rats twice heated to about $26 \%$

\section{EXPLANATION OF PLATE 1}

Fig. 1. Transverse section of testes from a rat 6 weeks after the second heat treatment, showing a 'partially' damaged tubule. Regeneration of the epithelium is evident but it is not possible to predict to what stage of the cycle regeneration will occur. $(\times 370)$.

Fig. 2. Transverse section of testes from a rat 6 weeks after the seventh heat treatment, showing a 'severely' damaged tubule. Note the lack of germ cells. $(\times 370)$.

Frg. 3. Transverse section of testes from a rat 6 weeks after the seventh heat treatment, showing advanced regeneration of the epithelium as far as 'cap-phase', spermatids in Stage VII. Note the absence of 'maturation-phase' spermatids. $(\times 370)$.

Fig. 4. Transverse section of testes from a rat, 24 weeks after the seventh heat treatment, showing the general appearance of the testes. Note tubules have either regenerated a complete epithelium or show no signs of regeneration. $(\times 120)$. 
PLATE 1
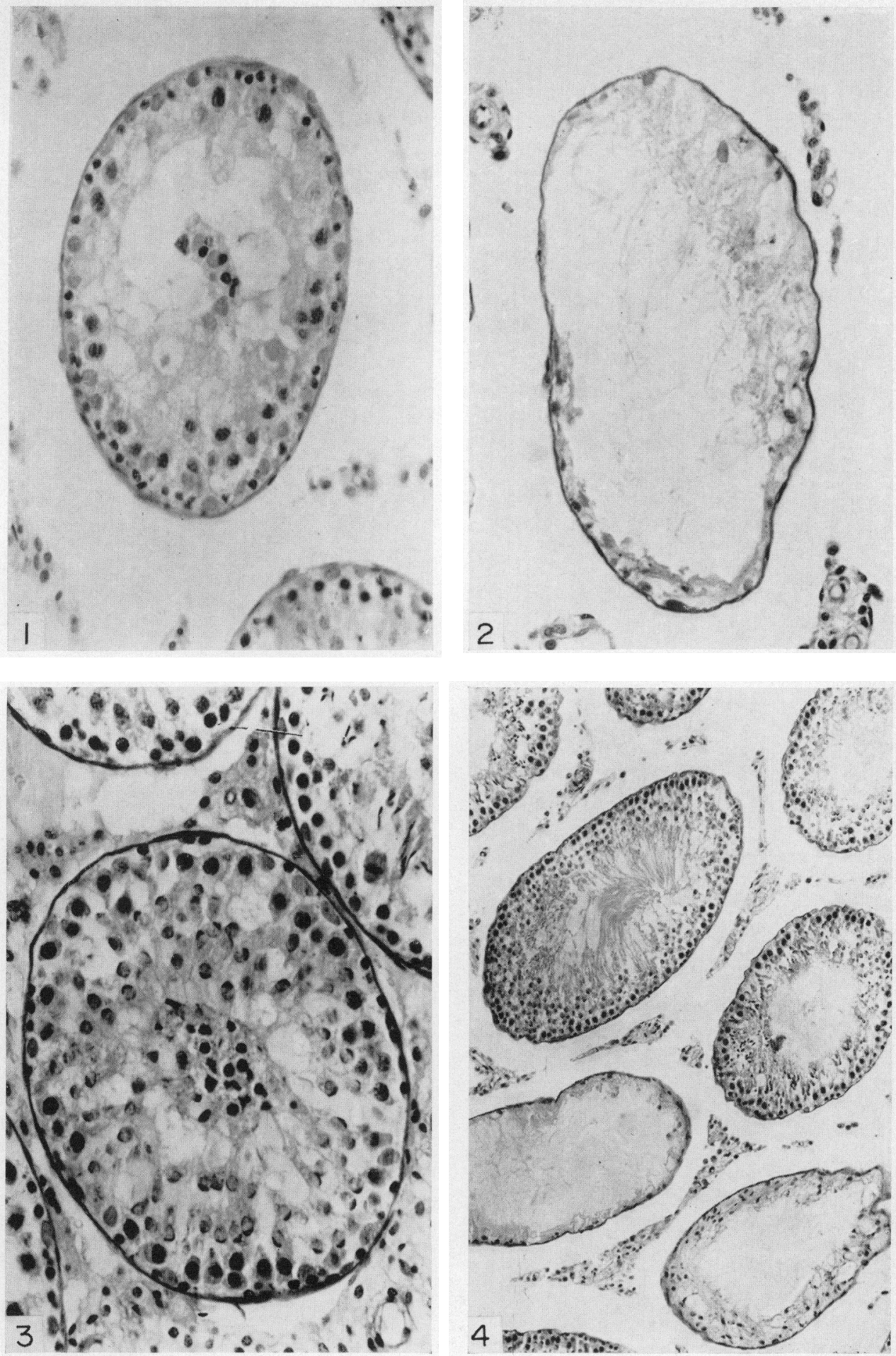

Facing p. 328) 


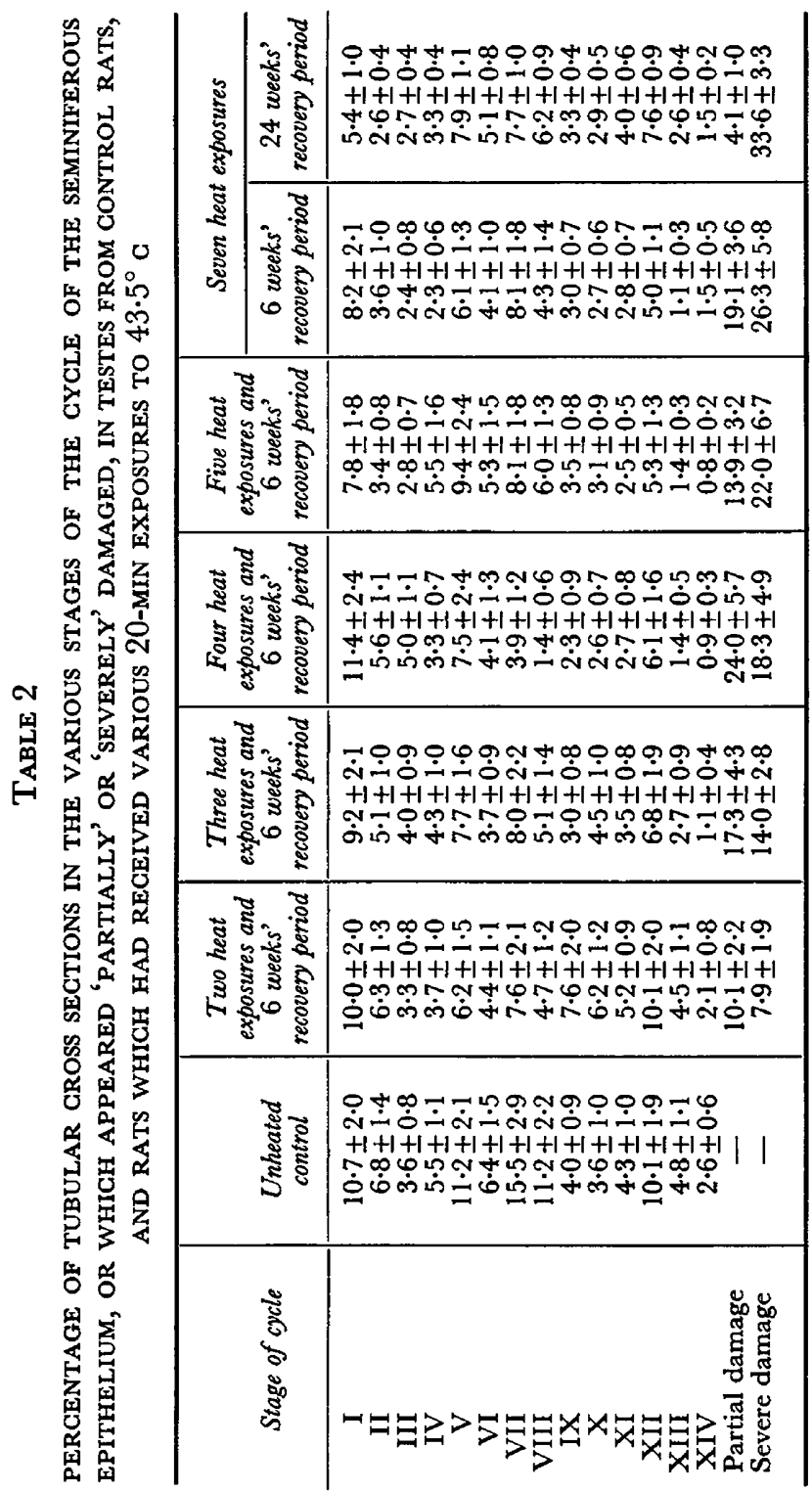


in the animals from the seven-times-heated group, and that approximately $4 \%$ of the tubules were so damaged at each treatment. The complete data are shown in Text-fig. 1 together with the calculated regression line. The equation for the regression line is $y=3.92 x+1 \cdot 54$. The response of different individuals was rather varied; however, the correlation coefficient of linear regression, $\mathrm{r}$, was 0.7 , which is statistically highly significant $(P=0.001)$. Presumably, these severely atrophic tubules were in a particularly sensitive stage at the time of the heat application, and did not subsequently become repopulated with germ cells. In the seven-times-treated group, the percentage of severely damaged tubules rose from $26.3 \%$ after 6 weeks' recovery to $33 \cdot 6 \% 24$ weeks after the last heat application, though this rise is not statistically significant.

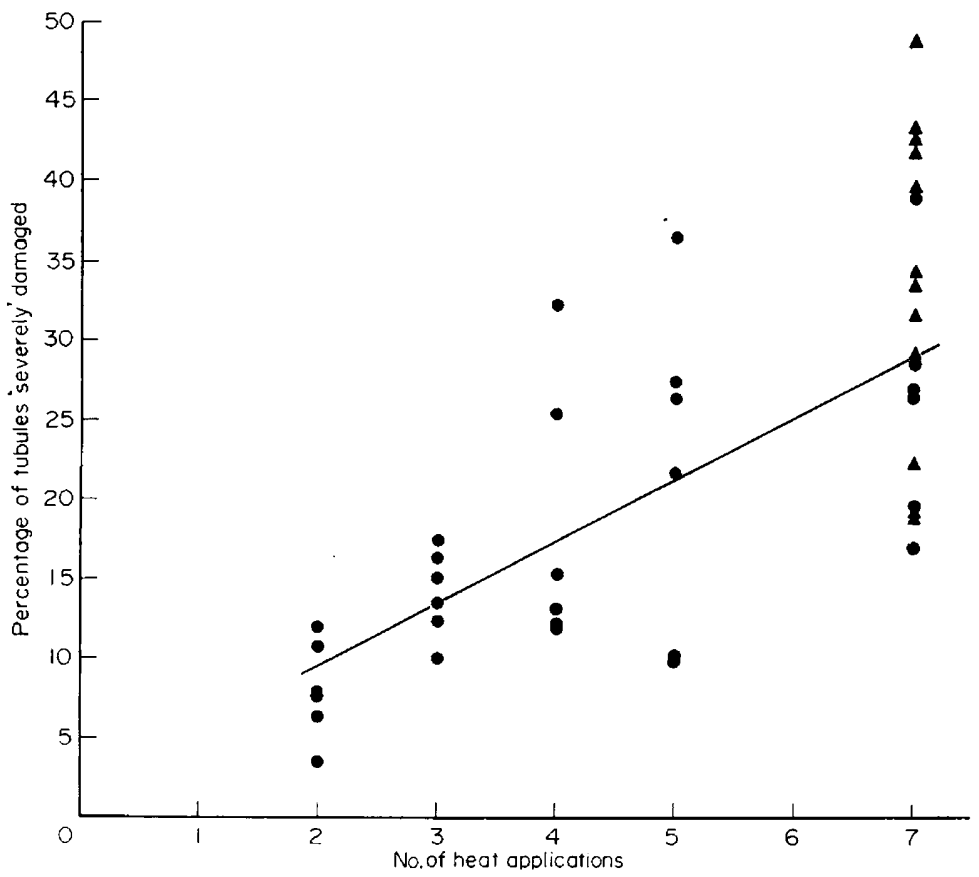

TEXT-FIG. 1. Effect of repeated heat treatments on the percentage of rat tubules showing 'severe' damage 6 weeks after each of the treatments $(\bullet)$ and 24 weeks after the seventh treatment $(\boldsymbol{\Lambda})$. The regression line was fitted by method of least squares and was fitted to the 6 -week recovery period ( $\bullet$ data only. The equation for the line is $y=3.92 x+1.54$, and the correlation coefficient of linear regression, $r,=0.7$.

The mean percentage of 'partially' damaged tubules did not show any consistent pattern with successive heat applications, but varied between 10 and $24 \%$ at any one time. Presumably, this kind of damage does not accumulate with successive treatments but is largely repaired between them. In the seventimes-heated group, the percentage of partially damaged tubules fell from $19 \%$ in the group after 6 weeks' recovery to $4 \%$ in the group after 24 weeks' recovery.

The heat treatments did not appear consistently to affect the distribution of the recovered tubules in the fourteen stages of the cycle. The main trend was a fall in the percentage of identifiable tubules concomitant with the increase in 
the percentage of 'severely' damaged tubules. However, only in Stages VII and VIII of the cycle were the percentages of tubules from the experimental groups consistently significantly lower than those of the control animals $(P=0.01$ in all cases).

The testes from the two animals which had not recovered fertility 24 weeks after the seventh heating were appreciably more damaged than any of the other twelve animals from this group. In one case, the testis was dramatically affected, $13.2 \%$ of the tubules being 'partially', and $64.8 \%$ 'severely', damaged. In the other animal, the damage was not so heavy, but was still more severe than in any of the twelve 'recovered' animals in this group, in that $6.8 \%$ of the tubules were 'partially', and $51 \%$ 'severely', damaged.

\section{DISCUSSION}

In a previous communication, Bowler (1967) reported on the results of the fertility trials with the males used in the present study. Their fertility was tested 6 weeks after each successive treatment and in no case was any male found to be fertile. Twelve of the fourteen males remaining from the final heat treatment recovered their fertility in $108 \pm 7 \cdot 2$ days as compared with a recovery period of $60 \pm 1 \cdot 6$ days for males given a single heat application only.

The fall in the testis weight of the experimental animals (Table I) is clearly the result of the extensive loss of germ cells, and the tendency for testis weight to fall with successive heat exposures is presumably due to the increasing numbers of tubules which are so affected (Table 2).

Seminal vesicle weight has been widely used as an indicator of the level of androgen output and therefore of the level of interstitial cell function. Recently, Llaurado \& Dominguez (1963) described androgen biosynthesis as being adversely affected by exposure to abdominal temperatures, and Hall (1965) confirmed this from a study in vitro. However, several workers, the most recent being Collins \& Lacy (1969), found that a single exposure at a moderately high temperature had no deleterious effect on the interstitium, as measured by seminal vesicle and prostate size. Furthermore, Lacy and his colleagues (1969) have shown that there is no change in androgen biosynthesis by isolated interstitial tissue following heat treatment at $43^{\circ} \mathrm{C}$. The fact that, in this present study, the seminal vesicle weights do not differ significantly from normal, even in the rats receiving seven heat treatments, is taken to mean that the repeated 20-min exposures at $43.5^{\circ} \mathrm{C}$ had no long-term effect on androgen biosynthesis or secretion. This confirms the earlier finding that the experimental males, although sterile, showed no loss of libido and displayed normal sexual behaviour when placed with a female (Bowler, 1967).

Some males were more sensitive to the heat treatments than others (cf. Collins \& Lacy, 1969), however, the histological appearance of the testis was very much the same in all groups except for the increase in 'severely' atrophic tubules with the number of times the rat had been exposed. That most of the tubules which are going to recover spermatogenesis do so within about 6 weeks suggests that the repeated treatments have not delayed recovery, which proceeds normally once it starts. 
The tubules can be divided into three groups according to their ability to regenerate the seminiferous epithelium following heat damage. In the majority, the epithelium is restored to an essentially normal condition after 6 weeks. It is possible that these are the tubules which were in Stages I to III or VII to XIV at the time of heat exposure, for Collins \& Lacy (1969) noted that these tubules were the least affected by a single heat treatment. The tubules which are described as 'partially' damaged, on the other hand, are composed of a variety of tubules in various states of regeneration. It is likely that those which show more advanced regeneration were in Stages IV to VI at the time of exposure, for Collins \& Lacy (1969) have shown that the late transitional and early pachytene spermatocytes present are very susceptible to heat. The epithelium in these stages would, therefore, have to regenerate from stem cells. Some tubules in the 'partially' damaged group show only very early stages of restoration of spermatogenesis, and in these, stem cells must also have been sensitive to the heat dosage.

The final type of damaged tubules were the 'severely' atrophic ones, in which no recovery of spermatogenesis was evident. This group constitutes an increasing proportion of tubules with successive heat treatments. This type of damage is cumulative, indicating that the capacity of these tubules to regain spermatogenesis is largely lost. The experiments took place over 36 weeks ( 60 weeks in the case of fourteen rats), a period some four times longer than the duration of the cycle of the seminiferous epithelium (Clermont \& Harvey, 1965), and so provided ample time for complete recovery of the majority of the tubules. It is most likely that the $4 \%$ of tubules, which were found to be 'partially' damaged in the animals allowed a 24-weeks' recovery following seven applications of heat, do represent recovery in 'severely' atrophic tubules since tubules which were 'partially' damaged after the seventh heating would have completely recovered within 24 weeks.

The damage caused in the 'severely' atrophic tubules could only occur through the destruction of stem cells. Although Collins \& Lacy (1969) and Steinberger \& Dixon (1959) describe spermatogonia as being in the most resistant population of cells, it would seem reasonable to propose that spermatogonia become heat-sensitive during mitosis. Considering the data of Dym \& Clermont (1970), the proposed sensitive periods would occur during the mitoses of type A spermatogonia in Stage IX (when type $A_{1}$ divide to give $A_{2}$ ), Stage XII (when $A_{2}$ divide and give rise to $A_{3}$ ), Stage XIV (when $A_{3}$ divide to produce $\mathrm{A}_{4}$ ) and Stage $\mathrm{I}$ (when $\mathrm{A}_{4}$ divide to produce intermediate type spermatogonia and type $A_{1}$ again). It is not known whether all these mitoses would be equally sensitive to heat, but perhaps the most critical time would be during the mitosis occurring in Stage I, for it is after this that fewest stem cells naturally exist in the epithelium. The duration of the heat treatments are short relative to the duration of any of these stages, and so not all tubules in a given stage at the time of heating would be expected to be acutely damaged, but only those in which mitosis was occurring at the time.

While type A spermatogonia are amongst the least susceptible elements to ischaemia in the rat (Steinberger \& Tjioe, 1969), these cells do become very sensitive during the mitoses occurring in Stages I, XII and XIV. Clegg (1963) 
also noted that spermatogonia undergoing mitosis were sensitive to artificial cryptorchidism, whilst 'resting' spermatogonia were resistant.

The significance of these results is that rat testes can withstand repeated applications of heat and still recover spermatogenic function. Furthermore, twelve of the fourteen rats, which received seven heat treatments, recovered fertility with about $30 \%$ of their tubules still in an atrophic condition. The point that may be of particular importance in human male fertility is that a small proportion of the tubules may be particularly heat sensitive, and that in the rat these tubules seem to have little capacity for the restoration of spermatogenesis.

\section{REFERENGES}

BowLER, K. (1967) The effects of repeated temperature applications to testes on fertility in male rats. F. Reprod. Fert. 14, 171.

Chowdhury, A. K. \& Steinberger, E. (1964) A quantitative study of the effect of heat on germinal epithelium of rat testes. Am. F. Anat. 115, 509.

CLEGG, E. J. (1963) Studies on artificial cryptorchidism: degenerative and regenerative changes in the germinal epithelium of the rat testes. 7 . Endocr. 27, 241.

Clermont, Y. \& Harvey, S. C. (1965) Duration of the cycle of the seminiferous epithelium of normal, hypophysectomized and hypophysectomized-hormone treated albino rats. Endocrinology, 76, 80.

Clermont, Y., Leblond, C. P. \& Messier, B. (1959) Durée du cycle de l'épithélium séminare du rat. Archs Anat. microsc. Morph. exp. 48, 37.

Collins, P. \& LACY, D. (1969) Studies on the structure and function of the mammalian testis. II. Cytological and histochemical observations on the testis of the rat after a single exposure to heat applied for different lengths of time. Proc. R. Soc. B, 172, 17.

Dym, M. \& Clermont, Y. (1970) Role of spermatogonia in the repair of the seminiferous epithelium following X-irradiation of the rat testis. Am. F. Anat. 128, 265.

HALL, P. F. (1965) Influence of temperature upon the biosynthesis of testosterone by rabbit testis in vitro. Endocrinology, 76, 396.

Lacy, D., Vinson, G. P., Collins, P., Bell, J., Fyson, P., Pudney, J. \& Pettitr, A. J. (1969) The Sertoli cell and spermatogenesis in mammals, p. 1019. In: Progress in Endocrinology. Ed. C. Gual. 3rd Int. Congr. Endocrinology, Mexico, 1968. Exerpta Med. Fdn, Amsterdam.

Leblond, C. P. \& Clermont, Y. (1952) Definition of the stages of the cycle of the seminiferous epithelium in the rat. Ann. N.Y. Acad. Sci. 55, 548.

Llaurado, J. G. \& Dominguez, O. V. (1963) Effect of cryptorchidism on testicular enzymes in androgen biosynthesis. Endocrinology, 72, 292.

Moore, C. R. (1924) Properties of the gonads as controllers of somatic and psychical characteristics. VI. Testicular reactions in experimental cryptorchidism. Am. F. Anat. 34, 269.

Moore, C. R. \& Oslund, R. (1923) Experiments on the sheep testis - cryptorchidism, vasectomy and scrotal insulation. Am. F. Physiol. 67, 595.

Moore, C. R. \& Quick, W. J. (1924) The scrotum as a temperature regulator for the testis. Am. 7 . Physiol. 68, 70.

Rooj, D. G. DE. (1968) Stem cell renewal and duration of spermatogonial cycle in the Goldhamster. Z. Zellforsch. mikrosk. Anat. 89, 133.

Steinberger, E. \& Dixon, W. J. (1959) Some observations on the effect of heat on the testicular germinal epithelium. Fert. Steril. 10, 578.

Steinberger, E. \& TJiOE, D. Y. (1969) Spermatogenesis in rat testes after experimental ischaemia. Fert. Steril. 20, 639.

Young, W. C. (1927) The influence of high temperature on the guinea pig testes: histological changes and effects on reproduction. 7 . exp. Zool. $49,459$.

Young, W. C. (1929) The influence of high temperature on the reproductive capacity of guinea pig spermatozoa as determined by artificial insemination. Physiol. Zoöl. 2, 1 .

Venkatachalam, P. S. \& Ramanathan, K. S. (1962) Effect of moderate heat on the testes of rats and monkeys. F. Reprod. Fert. 4, 51. 